\title{
The Impact Of Thermal Cycling In Humid Environments On Power Electronic Modules
}

\author{
Ningyan Wang ${ }^{1}$, Ian Cotton ${ }^{1}$, Kim Evans ${ }^{2}$
}

\begin{abstract}
The reliable operation of power electronic modules operating at high voltage is essential. The dielectric system within the power electronic module is reasonably simple but must be worked as hard as possible to achieve the highest module power densities. It is well known that a critical location in a power electronic module in terms of high voltage performance is the edge of the substrate metallisation where high electric fields can give rise to partial discharge within power electronic modules and can lead to eventual failure. This paper focuses on two particular issues. Firstly the performance of the gap between the substrate metallisation on which the collector and emitter of the device sit is examined. Secondly, the performance of the substrate-gel interface is examined once samples have been thermally aged in a humid environment.
\end{abstract}

Keywords: Power electronics, Partial discharges, Silicone insulation, Finite element methods, Humidity

\section{INTRODUCTION}

The increased desire to use power electronic modules at higher voltages in applications that demand reliable operation means that care must be taken in the design of the insulation system. Modules that operate at voltages over $5 \mathrm{kV}$ are now available and there will always be a drive to improve the power density of the module by raising voltages or by miniaturization. To further raise the voltage to increase the power density of a module, weak points in the dielectric system must be progressively improved.

A cross-section of a typical power electronic module is given in Figure 1. The module is composed of a metallised substrate soldered onto a baseplate which acts as the main heatsink for the module. The high voltage devices (silicon IGBTs / diodes or similar) are soldered onto one side of this metallised substrate. The substrate used in high voltage modules is usually made from aluminum nitride (AIN), a ceramic with good dielectric strength and good thermal conductivity. Wire bonds are used to make connections between the individual device terminals and external connections for gate drives / busbars (the main power connections between the device and the external terminals). The whole assembly is immersed in a soft encapsulant, typically a silicone gel, in order to provide the dielectric strength along the surfaces of the substrate, between the busbars and between any other parts of the module subject to high electric fields. An epoxy layer may then be added over the top of the entire dielectric system to implement extra protection from environmental factors such as moisture, dust and other contaminants as well as providing mechanical strength for the entire module.

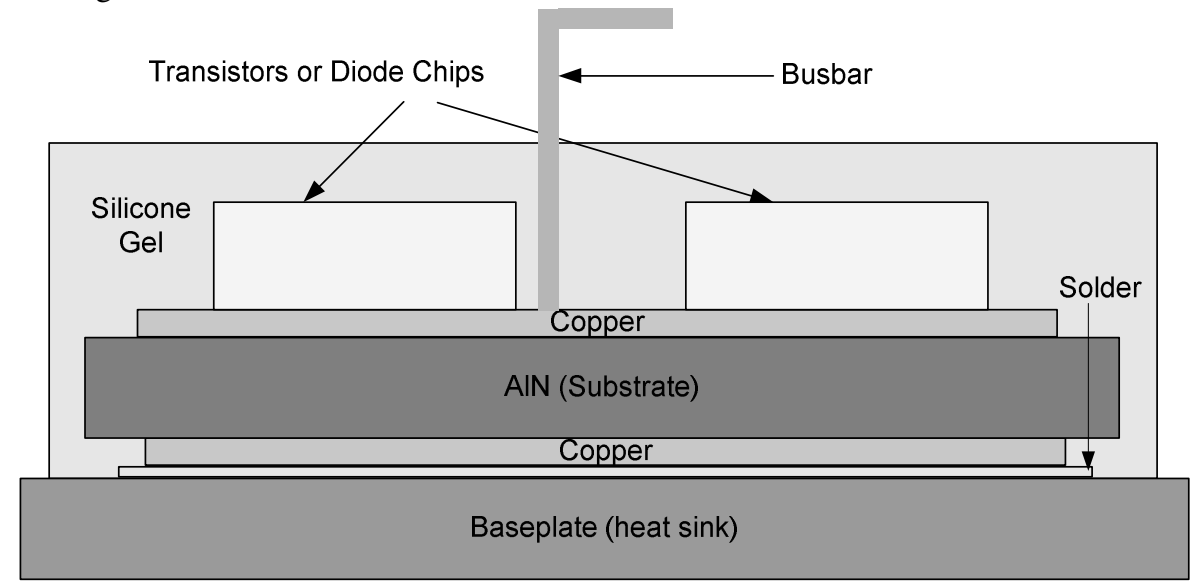

Figure 1: Cross-section view of typical power modules

Within a module, there are therefore three main dielectric systems. One is the substrate, typically made of aluminum nitride,

\footnotetext{
${ }^{1}$ Ningyan Wang and Ian Cotton are both with the School of Electrical and Electronic Engineering in the University of Manchester, UK. ${ }^{2}$ Kim Evans is with Dynex Semiconductors, Lincoln, UK
} 
must prevent breakdown between the high voltage devices and the baseplate. The second is the silicone gel which is used as an encapsulant and fills the entire module housing preventing partial discharges or breakdowns developing within the module. The final dielectric system is formed at the interface of these two components and it is this interface that is often the weakest point in a power module.

Testing of a substrate is fairly straightforward as they can be tested when produced, before they are used in the power electronic module. The electrical stress seen by the substrate when it is in use is also well represented during standard qualification test procedures. One potential cause is the presence of cracks within the microstructure of the material [1]. Partial discharge activity induced by these defects will ultimately limit the module lifetime as the dielectric integrity of the substrate is compromised.

The silicone gel used in the manufacture of power electronic modules is more difficult to control in manufacturing terms and more difficult to test. When pouring gels, it is essential to ensure the absence of air bubbles in the module as these can form locations in which partial discharge could take place. This is typically done by degassing the gels using a vacuum but this technique is not always efficient. There may be untested areas of silicone gel encapsulation when the module leaves the factory owing to the inability of the standard module test method to stress all parts of the silicone gel encapsulation [2]. This is due to the test being carried out with all terminals being bonded to high voltage while in operation they will be at different potentials [3]. Silicone gel should not age under the presence of an electric field alone [4] but may vary in performance according to the environmental conditions. For example, ambient temperature is known to have a significant impact on the dielectric performance of materials such as silicone gels. This is mainly due to the condensation of water out of the gels at lower temperatures, a process that significantly limits the dielectric performance of a gel [5].

Even though there can be quality issues with the substrate and gel materials as described above, the insulation system of a power module that limits the overall performance is at the interface between the silicone gel and the substrate at the edge of the substrate metallisation [6]. Electrical field simulation results show that maximum field within the module is around the edge of the substrate metallisation and this has been verified by optical detection [6]. Partial discharges from metallised edges of substrates at the silicone gel interfaces are the main sources of partial discharge in a power module [7]. While there are possible solutions such as increasing the size of a substrate tile, these are not generally compatible with the desire to have high power densities. Some researchers have investigated the use of semi-conductive coatings in this area to relieve the dielectric stress but these methods are not widely used in industry [8].

This paper details the electric field distribution within a power electronic module, paying particular attention to the edge of the substrate metallization (both at the edge of the substrate and within the collector-emitter gaps). The paper then reviews high voltage tests that have been carried out on samples designed to more accurately replicate the electric stress observed within the power electronic module during operation. These tests have been carried out with new samples and with a number that have been thermally cycled in both dry and humid conditions. Conclusions are reached regarding the impact of humidity on a power electronic module.

\section{Electrostatic Finite ElEMENT ANALysis STUDIES}

Electrical simulations for determining the electrical field distribution inside a power module are commonly used as they help to identify locations where the electric field strength is particularly high. These simulations can be used for layout optimization and to deliver quantitative results. The simulations can represent the power electronic module in its entirety and therefore usually model the substrate with its copper metallisation, the baseplate and the soft silicone gel that encapsulates the whole module. Such simulations can be of great use in reducing the product development cost.

In this study, the software used to produce electric field distributions is OPERA 3D, which is a general purpose electromagnetic analysis software. A power electronic module presents a number of challenges when it is modeled, these mainly being a result of the relatively thin size of some of the insulation layers in comparison to the length / width of the module. When the power electronic module is modelled in the finite element analysis (FEA) software, it is possible and necessary to simulate a number of different switching conditions that occur when the module is tested and when it is in use.

Power electronic modules destined for railway applications are tested according to IEC 61287 (Railway applications - Power Converters installed on board rolling stock - Part 1: Characteristics and test methods) [2]. According to this standard, all the terminals (including the gate drives) of the power electronic module are short circuited during a test and high voltage is applied to these short circuited terminals while the base plate is connected to ground. In the first ten seconds of the test, the voltage is ramped up to $1.5 \mathrm{Um} / \sqrt{2}$ (where $\mathrm{Um}$ is the highest voltage found in the module) and this voltage is then maintained for one minute. This is a standard overvoltage test to find weak areas in the dielectric system and will also cause any areas in which partial discharge may occur to begin discharging. Following this, the voltage is decreased over a ten second period to $1.1 \mathrm{Um} / \sqrt{ } 2$ and maintained for 30 seconds. During the last five seconds of this period, the level of partial discharge is measured. For a power 
electronic module, a typical maximum value of partial discharge allowed to pass this test is 10pC. For a subassembly, i.e. AlN substrates or silicone gel being tested individually, this value rises to $50 \mathrm{pC}$.

A module is not actually operated with all terminals connected to high voltage as is seen in this test. The test is carried out like this as it is not possible to impose a significant overvoltage across the semiconductor material used as the active part of the power electronic module. This means that there is a chance that insulation defects in power electronic modules will not be detected by this test method. This issue has been identified by another author who has suggested a solution that combines an AC test voltage with a DC offset [9].

The differences in the electric fields seen in the module during test and during operation are best highlighted using electric field simulations. For this purpose, a model of a $3.3 \mathrm{kV}$ four switch power electronic module has been created in Opera $3 \mathrm{D}$ as is illustrated in Figure 2 which gives a top view of the configuration. Four substrates are shown to be mounted on the baseplate. They consist of a $1 \mathrm{~mm}$ ceramic layer, a top metallization layer of $0.3 \mathrm{~mm}$ and a bottom metallization layer of $0.25 \mathrm{~mm}$. Each substrate has a $2 \mathrm{~mm}$ gap between the metallization and substrate edge with $1 \mathrm{~mm}$ gaps between the emitter, collector and gate drive metallisation. In most cases reported within this paper, only a quarter of this symmetrical system is modeled. The different conditions seen during test and operation are represented through the variation of boundary conditions within the model. The effect of transient voltage overshoots can also be included in the simulations by making adjustments to the magnitudes of the voltages imposed on specific sections of the module.

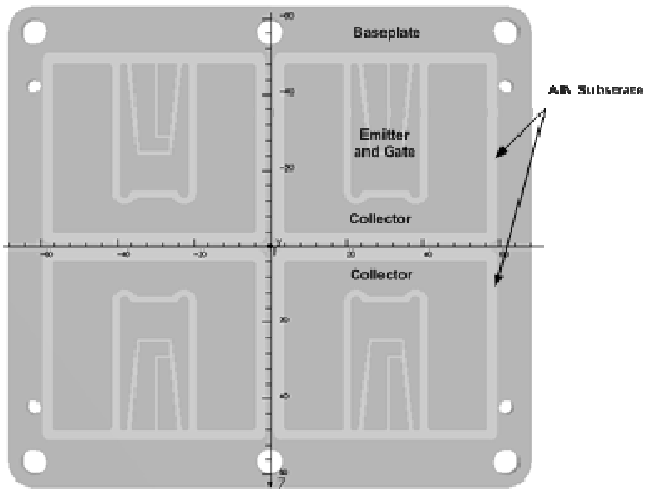

Figure 2: Top view of the modeled power electronic module consisting of four individual substrates - the lighter areas are plain AlN, the darker areas are metallisation

For the case when a power electronic module is under test, the resulting electric field distribution on the surface of substrate is as shown in Figure 3. The existence of a potential difference between the substrate metallisation and the baseplate means that the whole substrate is electrically stressed. However, the highest levels of field are present at the edge of the substrate metallisation which is also the location of a weakness in the dielectric system. This result clearly matches that of other researchers as discussed in the introduction section. High levels of electric field are shown across the collector-emitter gap (even though these are both at the same potential) and this will be examined in more detail in this section.

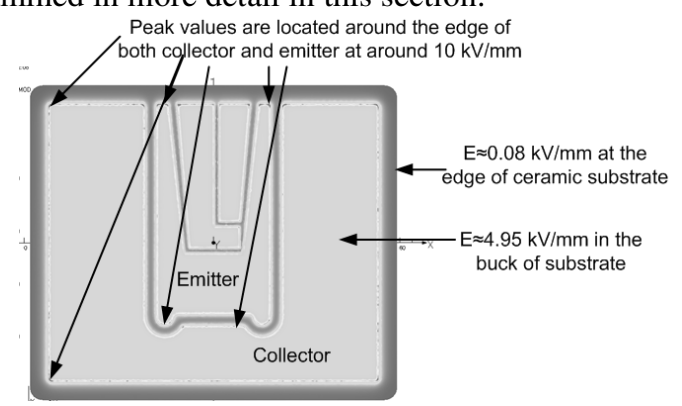

Figure 3: Electric field distribution on the surface of substrate during standard test 


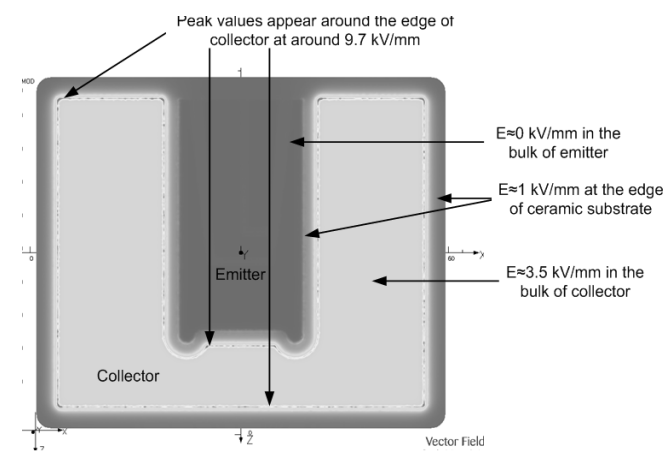

Figure 4: Electric field distribution on the surface of substrate in operation (when the switch is open)

In contrast, Figure 4 illustrates the electrical field distribution in the same location for a module that is operating. In the case shown, the switch is open and the collector is at high voltage $(3.3 \mathrm{kV})$ while the emitter and gate remain at earth potential. As for the case where the module is under partial discharge test (A voltage of $3.63 \mathrm{kV}$ is applied to all the terminals), the electrical field strength remains highest at the edge of substrate metallisation. The magnitudes of the peak electric field seen around the edges of the substrate are $11.0 \mathrm{kV} / \mathrm{mm}$ for the module under test and $9.76 \mathrm{kV} / \mathrm{mm}$ for the module in the worst operation condition (this being one where transient overvoltage overshoots exist).

The main difference between the two cases is the electric field within the collector-emitter gap. To examine the electric field in this area more closely, the magnitude and x-component (left to right) of the electric field are plotted for the location shown in Figure 5. Figure 6 gives the result.

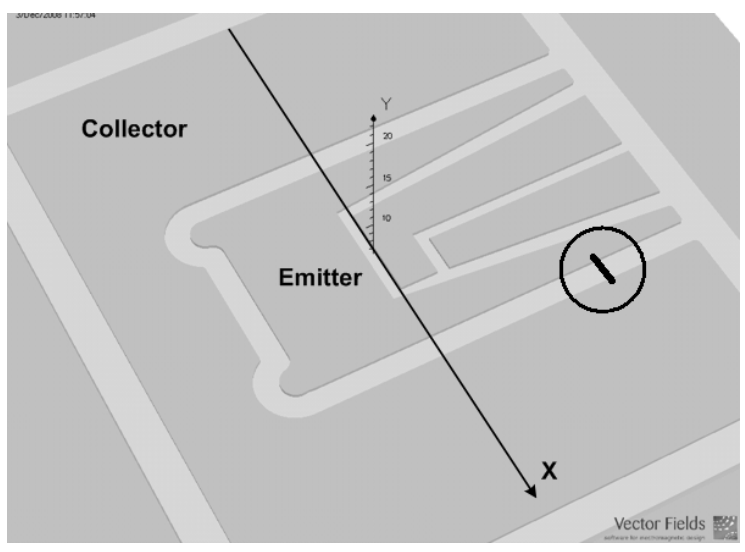

Figure 5: Location where the gap between collector and emitter are closely examined 


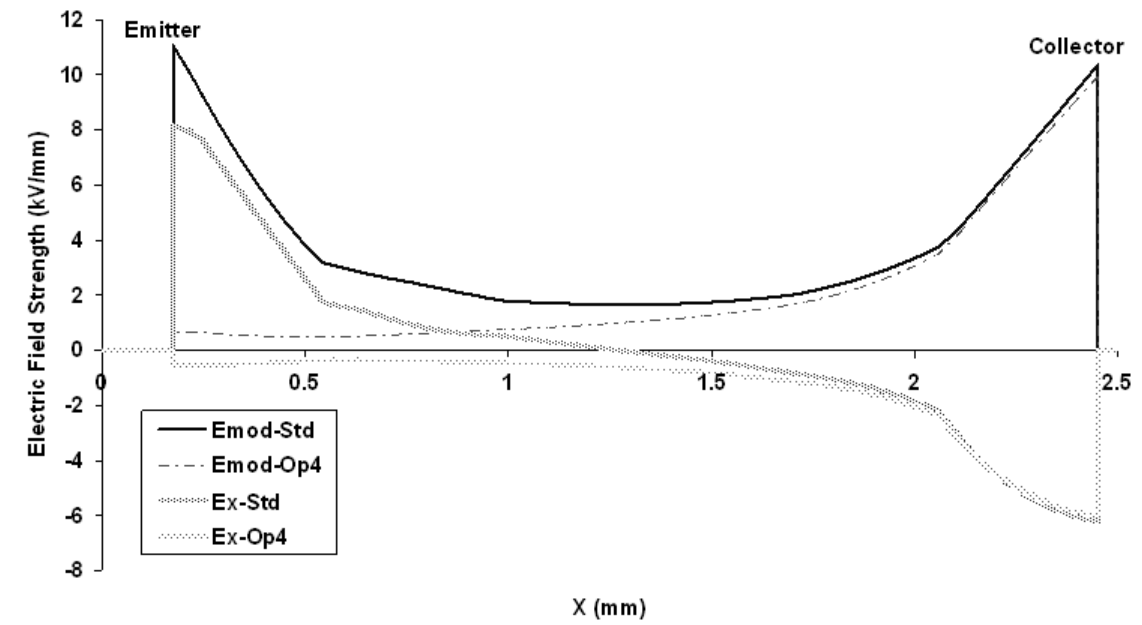

Figure 6: Field distribution across the gap under standard test and worst case during operation (Emod-Std: Total electric field under standard test condition. Emod-Op4: Total electric field under the worst operating condition. Ex-Std: Electric field along the x-axis under standard test condition. Ex-Op4: Electric field along x-axis under the worst operating condition)

The lines labeled 'std' on the graph refer to the standard test condition where the emitter and collector are both at the same potential. At both the edge of the collector and the emitter, the magnitude of the electric field is high owing to the field enhancement taking place at the edge of the metallisation. The electric field in that region is mostly made up of a component in the x-plane, with opposite electric field polarities being observed on the collector and the emitter. The higher than zero magnitude of field at the centre of the gap is in due to the vertical component of electric field going through the substrate. The opposing polarity of the electric field at the collector and emitter means that discharges will not progress to breakdown in the collector-emitter gap during a standard test. It is, however, accepted that partial discharges could initiate. In this case, all module failures that involved partial discharge initiation from the edge of the substrate metallization would be expected to take place around the outer perimeter of the substrate. The maximum field observed in standard test is $11.1 \mathrm{kV} / \mathrm{mm}$ at the edge of emitter.

When the electric field distribution is examined for the operating condition where only the collector is at high voltage, the high level of electric field is only observed in the region around the collector ( $x=2.5 \mathrm{~mm}$ on the graph) with a maximum field of $9.9 \mathrm{kV} / \mathrm{mm}$. The main difference relates to the electric field in the x-plane being unidirectional. In this case, the enhanced electric field close to the collector will still initiate discharge but the unidirectional nature of the field should also allow any discharge to propagate and cause a complete breakdown. This would therefore suggest that failures of this gap would be observed when testing samples with the collector at high voltage and the emitter grounded (but without any devices present). This issue is examined in the next section where experimental measurements are taken.

The electric field simulations therefore highlight some key differences between the module under test and in operation. When under test, partial discharge inception at the edge of the substrate metallization will be observed but will not necessarily lead to breakdown. All edges of the substrate metallization will be tested. However, certain locations (such as the silicone gel between busbars) will not be tested adequately. In operation, partial discharges are more likely to cause breakdown of the collector emitter gap owing to the unidirectional field. In addition, gaps between high voltage busbars and similar will also be more prone to breakdown.

\section{TESTING OF GEL SUBSTRATE SAMPLES}

To examine some of the issues presented in the previous section and to examine the relative performance of gels and substrates following thermal cycling in humid conditions, experimental measurements have been carried out. As can be seen in Figure 7, samples have been fabricated using a metallised aluminum nitride substrate from a commercial supplier. Placed on the collector and the emitter are two soldered metallic connections that are used to connect wires for eventual connection to the HV test equipment. The collector (C) is connected to the high voltage electrode while the emitter (E) and all the small metallisation components within are connected to ground. This is a similar test arrangement to that used by other researchers [7, 10, 11] with the exception of the way the collector and emitter are connected. This type of test should more accurately replicate the condition within the power electronic module when the device is open-circuit and not that of the standard test. It is possible for this to be done using this test object as the substrates are not populated with devices. 


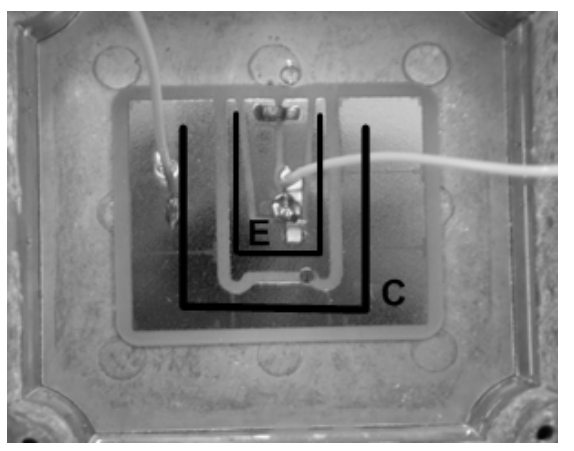

Figure 7: Substrate embedded in gel as used in the partial discharge and breakdown tests

The samples were prepared as follows. The wires were soldered to the metallized pads. Following inspection of the samples to ensure that they are clean, they are placed in a metal container whose sides are a sufficient distance from the edge of the metallisation so as not to influence the electric field. A total of about $100 \mathrm{~g}$ silicone gel is then poured into the container to encapsulate the substrate. The silicone gel used in these tests is a soft and clear two-component system designed for the encapsulation and protection of electronics components, suitable for working in the temperature range between $-55^{\circ} \mathrm{C}$ to $200^{\circ} \mathrm{C}$. It has a dielectric strength of $18.5 \mathrm{kV} / \mathrm{mm}$ according to the datasheet. Once the silicone gel was poured, the samples were degassed under a vacuum for a period of 15 minutes before being cured in an oven at a temperature of $90^{\circ} \mathrm{C}$ for one hour.

Three sets of samples were manufactured with 30 samples per set. Set 1 had 25 samples that were thermal cycled from $20^{\circ} \mathrm{C}$ to $90^{\circ} \mathrm{C}$ with twenty minute ramps and dwells at $25 \% \mathrm{RH}$. Five samples of Set 1 were stored in a desiccator as controls at $25 \% \mathrm{RH}$. Set 2 ( $85 \% \mathrm{RH}$ w/o cover) had 25 samples that were thermal cycled from $20^{\circ} \mathrm{C}$ to $90^{\circ} \mathrm{C}$ with twenty minute ramps and dwells at $83 \%$ RH. Five samples of Set 2 were stored in a desiccator as controls at $83 \%$ RH. During the testing of Set 2, water collected on the top of the samples. Set $3(85 \% \mathrm{RH}$ with cover) was therefore tested in the same manner as Set 2 but also had a cover to prevent water from pooling on top of silicone gel.

Each of the sets of 30 samples was cycled for a different period of time to investigate whether thermal cycling would have any impact on the dielectric performance of the test system. A Thermotron environmental chamber (model no: SM-8-3800) was adopted in this study as it provides control over both temperature and humidity. As the relative humidity could only be controlled reliably within the temperature range of between $10^{\circ} \mathrm{C}$ and $95^{\circ} \mathrm{C}$, the thermal cycling was carried out between room temperature $\left(20^{\circ} \mathrm{C}\right)$ and the highest temperature seen in the dielectric material used in power modules $\left(90^{\circ} \mathrm{C}\right.$, corresponding to $125^{\circ} \mathrm{C}$ in the junction [12] [13] ). For sets one and two, samples were tested in the order shown in Table 1. Twenty-five of the thirty samples were thermally cycled while 5 samples were kept in a dry or humid desiccator as a control as required by that set. As no significant effect of cycling duration was found in the first two sets, all samples in set three were cycled for the full 56 days or 1008 cycles.

\begin{tabular}{|c|c|}
\hline Number Of Days Cycling & $\begin{array}{c}\text { Number Of Samples Tested at } \\
\text { Each Data Point }\end{array}$ \\
\hline 0 & 5 \\
\hline $1,3,7,14,28$ & 3 \\
\hline $56(1008$ cycles $)$ & 5 \\
\hline $\begin{array}{c}\text { Not cycled, kept 56 days in desiccator at 25\% or 83\% RH as } \\
\text { required for that set }\end{array}$ & 5 \\
\hline
\end{tabular}

Table. 1: Sampling plan in dry and wet conditions

When the samples were tested, they were placed in a darkened enclosure in which a night-vision camera was located. This allowed visible records of discharge to be collected. A transformer, fed from a variable voltage mains supply, was used to energise the samples. A conventional partial discharge measurement circuit according to IEC 60270 was used to measure the discharge inception voltage and partial discharge distribution. A typical image captured from the night vision camera (Yukon, NV24024, sensible of Infra-red wavelength of $850 \mathrm{~nm}$ ) during the tests is shown in Figure 8. Discharge can be seen in this example (as indicated by the circled regions) both on the outer edge of the collector as well as within the collector-emitter gap. It is this latter form of discharge that would not necessarily have been observed by other researchers owing to the test configuration used. The location of failures in the tests correlated with the discharge locations observed by the camera. 


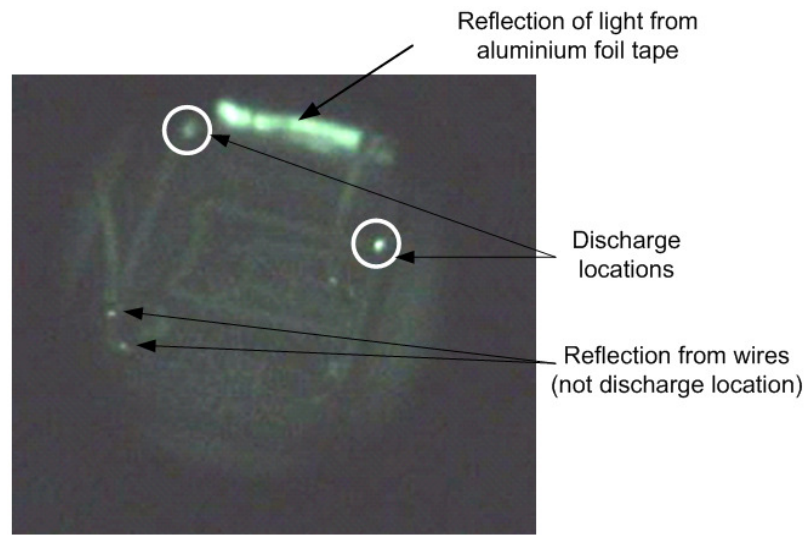

Figure 8: Discharge observed on substrate-gel interface between collector and emitter

During testing, the voltage was steadily raised until the partial discharge inception voltage was reached. At this point, 60 seconds of partial discharge data was collected by the Lemke LDS6 detector. Following this, the voltage was further increased until breakdown of the test piece took place. Figure 9 shows the failure location in one of the test samples. Breakdown occurred within the gap between the collector and the emitter, a bubble which disappeared after a few days leaving a thin black mark. Only four samples out of 60 that broke down at the outside edge of the metallisation. This is in contrast to the results of other researches $[6,7]$ but is to be expected owing to the alternative test configuration and confirms the findings of the electric field modeling. This is significant as it suggests that modules in service are vulnerable to electrical discharge at these locations. It demonstrates the importance of partial discharge measurements being carried out on power electronic modules since the use of the standard test technique would only lead to partial discharge and not breakdown.

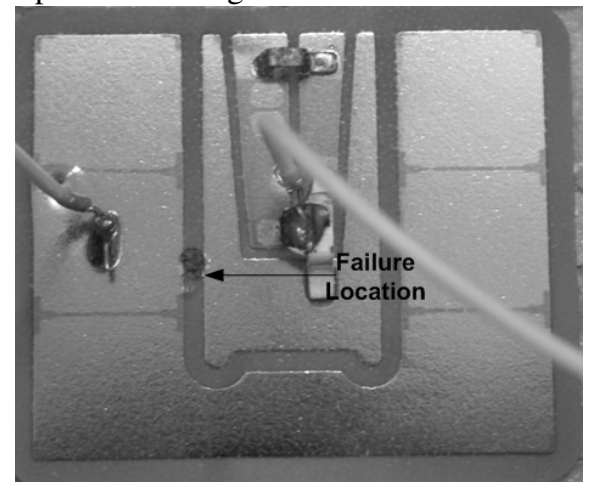

Figure 9: Failure location in one of the tested samples

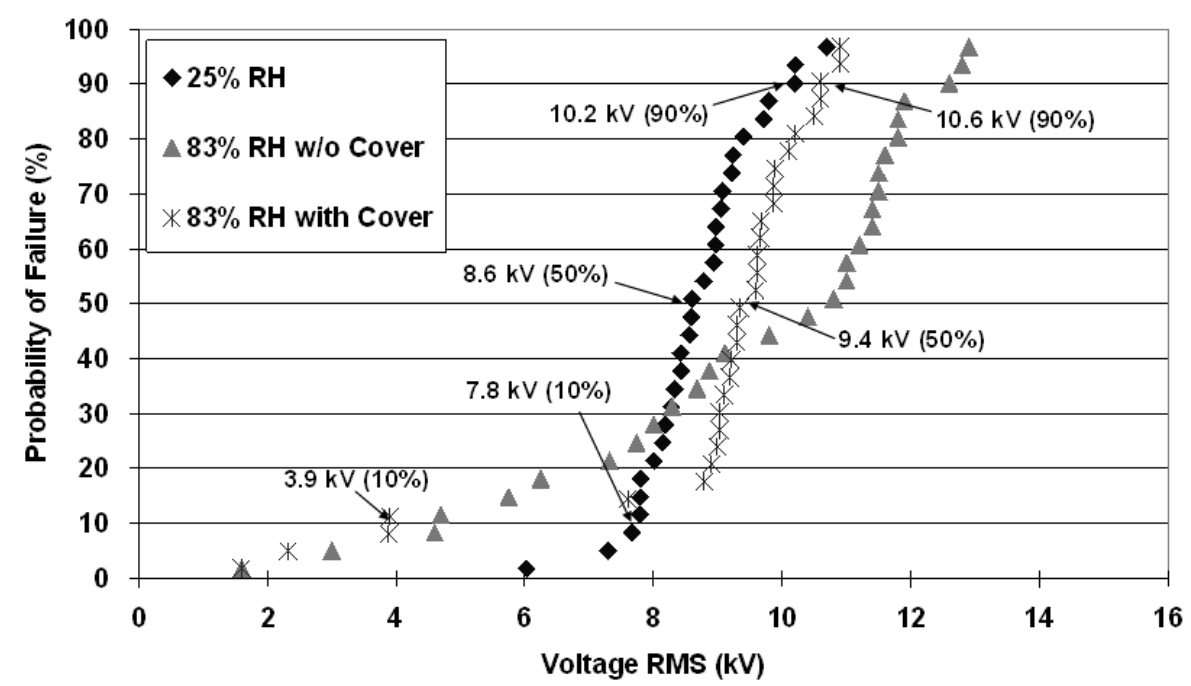

Figure 10: Cumulative probability of PD inception voltage of samples in all three sets including control samples 
Figure 10 shows the cumulative probability of the voltage causing PD inception for the samples aged under low and high humidity conditions. Initially, examining the results of the tests carried out under dry conditions, it can be seen that the probability of failure in PD inception are distributed over a fairly small voltage range, the difference between the $10^{\text {th }}(7.8 \mathrm{kV})$ and $90^{\text {th }}(10.2 \mathrm{kV})$ percentile being just over $2 \mathrm{kV}$. The data showed that there is no significant influence of the duration of the thermal cycling in dry conditions as samples with few thermal cycles show a similar average PD inception voltage as samples with many thermal cycles as is shown in Table 2.

\begin{tabular}{|c|c|c|c|c|c|}
\hline & \multicolumn{2}{|c|}{ Set 1 - 25\% RH } & \multicolumn{2}{c|}{ Set 2 - 83\% RH w/o Cover } & $\begin{array}{c}\text { Set 3-83\% RH } \\
\text { with Cover }\end{array}$ \\
\hline & $\begin{array}{c}\text { First 11 samples } \\
(0,1,3 \text { days })\end{array}$ & $\begin{array}{c}\text { Last 11 samples } \\
(14,28,56 \text { days })\end{array}$ & $\begin{array}{c}\text { First 11 samples } \\
(0,1,3 \text { days })\end{array}$ & $\begin{array}{c}\text { Last 11 samples } \\
(14,28,56 \text { days })\end{array}$ & All samples \\
\hline $\begin{array}{c}\text { Average PD Inception } \\
\text { Voltage / kV }\end{array}$ & 8.9 & 8.8 & 9.5 & 10.3 & 8.74 \\
\hline $\begin{array}{c}\text { Standard Deviation / } \\
\text { kV }\end{array}$ & 1.2 & 0.5 & 2.7 & 2.7 & 2.4 \\
\hline
\end{tabular}

Table. 2: Comparison of results from samples aged at different times for low and high humidity conditions

In comparison, the cycling of samples into humid conditions with and without a cover has had a dramatic impact on the performance of the test samples. Two issues are apparent, the extremely low voltages at which some samples initiated partial discharge and the apparent improvement of some other samples. The difference between the $10^{\text {th }}(3.9 \mathrm{kV}$, Set 3$)$ and the $90^{\text {th }}$ $(10.6 \mathrm{kV}$, Set 3$)$ percentile of partial discharge inception has now increased to between $6 \mathrm{kV}$ and $8 \mathrm{kV}$. The average PD inception voltage has, however, increased slightly. This particular issue will be discussed in some more detail below.

When the results for the high humidity case are examined as a function of age as shown in Table 2 , it is clear that there remains no relationship between the time the samples were in the humidity chamber and the reduction in voltage capability. Low values of voltage were noticed in test samples from day 1 onwards. This would suggest that any influence of water quickly manifests itself in the samples and that the temperature cycling conditions used in these tests are not significant. It had initially been thought that the large amount of scatter in the samples cycled in a high humidity could be due to water ingress. Water condensed on the top of the chamber and could directly drip onto the samples. While the silicone gel should prevent penetration to the substrate surface, a second set of tests were carried out where the samples had a cover on top to avoid any condensed water drops. However, even in this case there were still a number of particularly low results among these samples in the partial discharge test.

In addition, the control samples that were kept in a humid environment that underwent no temperature cycling (and in which no water fell onto the samples) showed a similar change with some significantly reduced PD inception voltages being noted. It was therefore clear that water alone was the cause of the significant reduction in the performance of a number of samples and that associated thermal cycling was not an aggravating factor.

The reduction in the PD performance of some samples is therefore thought to be associated with penetration of water through the sample to the substrate-gel interface. The presence of the water causes PD inception at a lower voltage and in a number of cases, instant breakdown with no PD being measured (these low values also being observed in a cumulative probability plot of breakdown voltage as shown in Figure 11). 


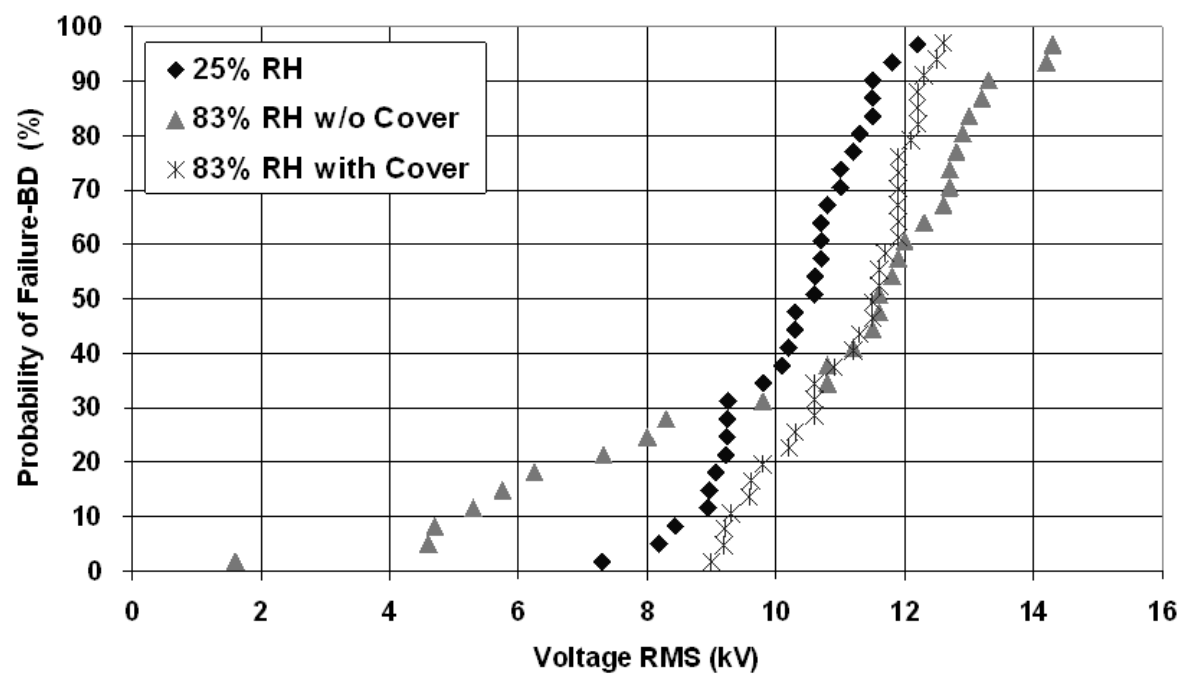

Figure 11: Cumulative probability of breakdown voltage of samples in all three sets including control samples

The result that is difficult to explain in these tests relates to the increase in performance of some of the samples when cycled in a humid environment. The samples were produced at different times and it is possible that the silicone gel used for the samples aged in a high humidity environment was of better quality than that used for the other sample set. This would result in an apparent increase in performance for the modules less affected by the humidity but would not protect those where humidity had a significant influence. A second possibility is that the gel changes in electrical characteristics when aged in a humid environment. It is well known from work by other researchers that a reduction in breakdown strength occurs within wet gels [14, 15] in all cases (i.e. both at high and low probabilities of failure). The interfacial adhesion of silicone gel to substrate surface depends on both the polymer and surfaces to which it is bonded. However, according to the findings of G. Finis and A. Claudi [15], they suggest that the performance of an interface is mainly based on the silicone gel itself, which would suggest that the strength of the test samples aged under high humidity conditions should only fall. This does not correlate with the data but this could again be a result of the gels being used having a slight difference in dielectric strength. The remaining alternative is that the permittivity of the gel changes on a local basis or throughout the bulk. However, measurements of bulk permittivity of gels aged in low and high humidity have failed to show any difference.

\section{COMPARISON OF SIMULATIONS AND EXPERIMENTS}

The substrate tested in this work is intended for use in a module that operates at $3.3 \mathrm{kV}$. Simulation results in Section II show that in operation the substrate gel interface of a $3.3 \mathrm{kV}$ module will see a maximum field of around $9.9 \mathrm{kV} / \mathrm{mm}$ and in standard test the peak value will be $11.1 \mathrm{kV} / \mathrm{mm}$. Through the finite element analysis, this required electric field strength in operation can therefore be compared with the test results recorded in Section III by setting the boundary conditions to the partial discharge inception voltage shown in each percentile in Figure 10 to derive the peak value of field at each percentile. Table 3 lists the electric field encountered in the experiments at different percentiles in different ageing conditions. Only Set 1 and Set 3 have been included in this table as Set 3 better represents the reality of a power module in a highly humid environment than Set 2 . All these maximum fields occur across the gap between collector and emitter. It is obvious from this table that even when stored in a high humidity condition, $90 \%$ of the samples will be able to survive a maximum field of $11.7 \mathrm{kV} / \mathrm{mm}$. Although this value seems to exceed the maximum field a $3.3 \mathrm{kV}$ power module will see in operation and in standard test, it is rather close to the desired value (of $11.1 \mathrm{kV} / \mathrm{mm}$ ). Compared to the value at low humidity condition which shows a peak field of $23.5 \mathrm{kV} / \mathrm{mm}$ at $10^{\text {th }}$ percentile, it is clear that the use of power electronic modules in a high humidity environment will lead to an increased likelihood of failure and should be a consideration when attempting to make modules more compact / increase the voltage to reach better power densities.

\begin{tabular}{|c|c|c|c|}
\hline & $10 \%$ & $50 \%$ & $90 \%$ \\
\hline PD inception field in Set 1-25\% RH (from experiments) & 23.5 & 25.9 & 30.7 \\
\hline $\begin{array}{c}\text { PD inception field in Set 3-83\% RH with Cover (from } \\
\text { experiments) }\end{array}$ & 11.7 & 28.3 & 31.9 \\
\hline
\end{tabular}

Table.3: Partial discharge inception field at $10^{\text {th }}, 50^{\text {th }}$ and $90^{\text {th }}$ percentiles $(\mathrm{kV} / \mathrm{mm})$

\section{CONCLUSIONS}

Investigations into the performance of dielectric materials used in power electronic modules have been described in this paper. 
Finite element software has been utilized as a simulation tool to analyse experiment results and to localise weak points in the module. Experiments have carried out using samples fabricated from metallised substrates that are embedded with silicone gel.

The simulations showed that the electric fields observed in a module in an operating condition are different to those seen when the standard test method is used. The insulation system may not be tested in certain locations (such as between the busbars) by use of the standard test. However, the standard test will allow partial discharge inception of the edges of the substrate metallization, the area of the power electronic module dielectric systems that is likely to be the weakest.

Samples with a substrate embedded in gel have been stored in desiccators and thermally cycled at $25 \%$ and $83 \%$ RH for up to 56 days. The results show that there is no obvious effect due to $20^{\circ} \mathrm{C}$ to $90^{\circ} \mathrm{C}$ thermal cycling but a large effect due to the relative humidity. However, this result is only valid given operating conditions between $20^{\circ} \mathrm{C}$ and $90^{\circ} \mathrm{C}$. A slightly higher average but much large scatter in voltage has been observed in both the partial discharge and breakdown results of substrate-gel samples cycled in a high humidity environment. The exposure to a high humidity environment results in a rapid loss of dielectric breakdown strength for some samples.

It is clear that a significant design margin must be maintained when designing power electronic modules to allow for decreasing performances of the silicone gel / substrate interface in conditions of high humidity.

\section{REFERENCES}

[1] T. Ruemenapp and D. Peier, "Investigation of the ageing performance of AlN-ceramic used in high-power-semiconductors," presented at Eighth International Conference on Dielectric Materials, Measurements and Applications, pp. 285-290, 2000.

[2] IEC61287, "Railway applications -Power convertors installed on board rolling stock," 2005.

[3] F. Breit, E. Dutarde, J. Saiz, T. Lebey, D. Malec, and S. Dinculescu, "Partial discharge detection in power modules," presented at Power Electronics Specialists Conference, IEEE 33rd Annual, pp. 748-752, vol. 2, 2002.

[4] T. Ebke, A. Khaddour, and D. Peier, "Degradation of silicone gel by partial discharges due to different defects," presented at Eighth International Conference on Dielectric Materials, Measurements and Applications, Edinburgh pp. 202-207, 2000.

[5] G. Finis and A. Claudi, "Silicone gel as an insulation material for HV-insulation applications," presented at Proceedings of the XIVth International Symposium on High Voltage Engineering, Tsinghua University, Beijing, China, pp. 1-5, 2005.

[6] J. H. Fabian, S. Hartmann, and A. Hamidi, "Analysis of insulation failure modes in high power IGBT modules," presented at Industry Applications Conference, Fourtieth IAS Annual Meeting. , pp. 799-805, vol. 2, 2005.

[7] G. Mitic and G. Lefranc, "Localization of electrical-insulation and partial-discharge failures of IGBT modules," IEEE Transactions on Industry Applications, vol. 38, pp. 175-180, 2002.

[8] G. Mitic, T. Licht, and G. Lefranc, "IGBT module technology with high partial discharge resistance," presented at Industry Applications Conference, Thirty-Sixth IAS Annual Meeting, Chicago, IL pp. 1899-1904, vol. 3, 2001.

[9] T. Lebey, S. Dinculescu, and D. Malec, "Partial discharges testing of power modules," presented at Solid Dielectrics, ICSD, pp. 896-899 Vol.892, vol. 2, 2004.

[10]M. T. Do, J. L. Auge, and O. Lesaint, "Optical measurement of partial discharges in silicone gel under repetitive pulse voltage," presented at International Symposium on Electrical Insulating Materials, Kitakyushu, Japan, pp. 360-363, vol. 2, 2005.

[11]T. A. T. Vu, J. L. Auge, and O. Lesaint, "Low temperature partial discharge properties of silicone gels used to encapsulate power semiconductors," presented at IEEE Conference on Electrical Insulation and Dielectric Phenomena, Virginia Beach, VA pp. 421-424, 2009.

[12]S. Catellani, J. C. Crebier, C. Schaeffer, and T. Marsala, "Thermal and electrical ageing of DBC substrates," presented at Power Electronics Specialists Conference, IEEE 32nd Annual, pp. 1955-1960 vol. 1954, vol. 4, 2001.

[13]"High Isolation Single Switch IGBT Module," Dynex Semiconductor 2005.

[14]G. Finis and A. Claudi, "Silicone gel as an insulation material for HV-insulation applications," presented at Proceedings of the XIVth International Symposium on High Voltage Engineering, Tsinghua University, Beijing, China, pp. I1-5, 2005.

[15]G. Finis and A. Claudi, "On the Electric Breakdown Behavior of Silicone Gel at Interfaces," Dielectrics and Electrical Insulation, IEEE Transactions, vol. 15, pp. 366-373, 2008. 